Provided for non-commercial research and education use. Not for reproduction, distribution or commercial use.

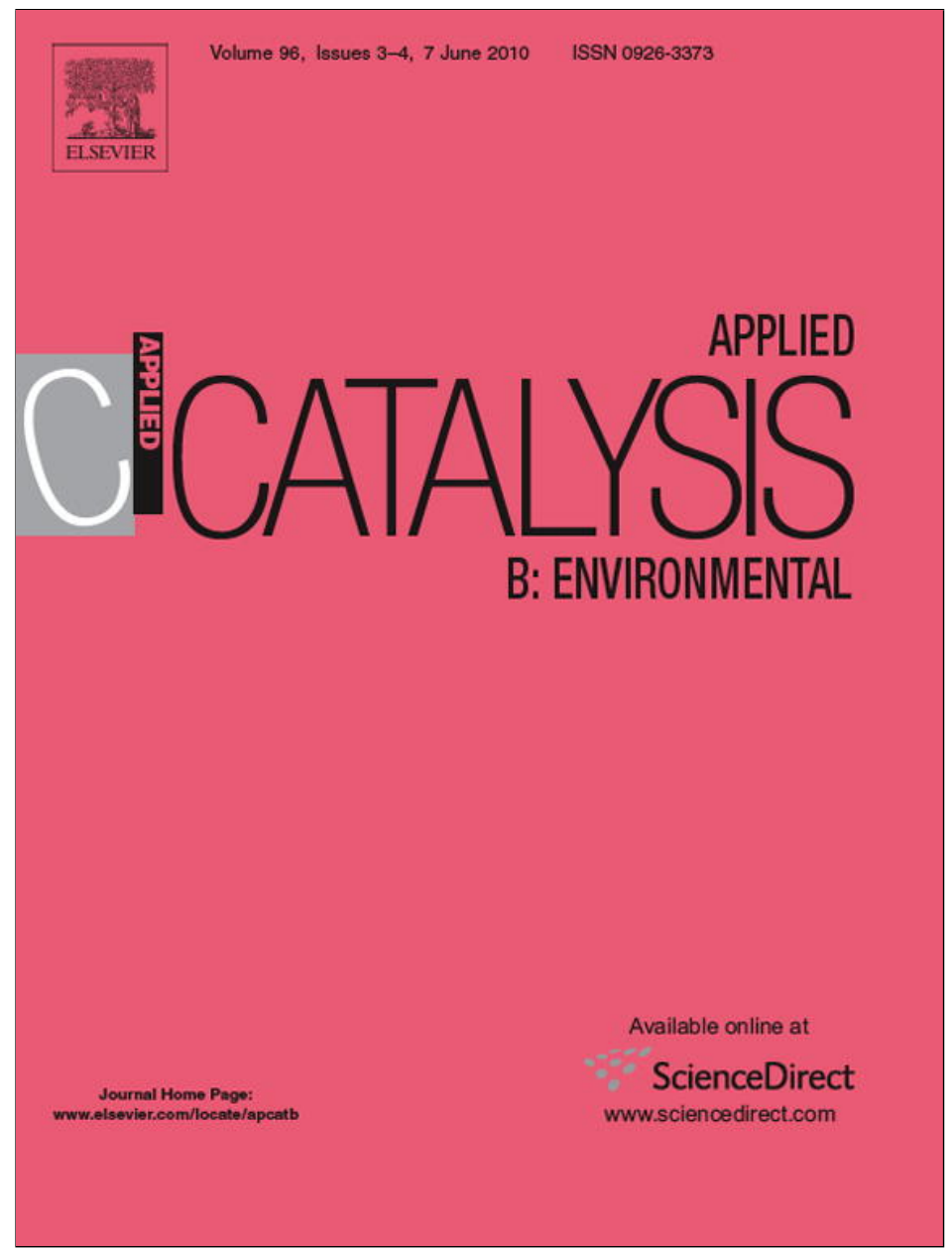

This article appeared in a journal published by Elsevier. The attached copy is furnished to the author for internal non-commercial research and education use, including for instruction at the authors institution and sharing with colleagues.

Other uses, including reproduction and distribution, or selling or licensing copies, or posting to personal, institutional or third party websites are prohibited.

In most cases authors are permitted to post their version of the article (e.g. in Word or Tex form) to their personal website or institutional repository. Authors requiring further information regarding Elsevier's archiving and manuscript policies are encouraged to visit:

http://www.elsevier.com/copyright 


\title{
Solar photoactivity of nano-N-TiO 2 from tertiary amine: role of defects and paramagnetic species
}

\author{
Francesca Spadavecchia ${ }^{a}$, Giuseppe Cappelletti ${ }^{\mathrm{a}, *}$, Silvia Ardizzone ${ }^{\mathrm{a}}$, Claudia L. Bianchi ${ }^{\mathrm{a}}$, \\ Serena Cappelli ${ }^{a}$, Cesare Oliva ${ }^{a}$, Paolo Scardi ${ }^{b}$, Matteo Leoni ${ }^{b}$, Paola Fermo ${ }^{c}$ \\ a Dipartimento di Chimica Fisica ed Elettrochimica, Università degli Studi di Milano, Via Golgi 19, 20133 Milano, Italy \\ ${ }^{\mathrm{b}}$ Department of Materials Engineering and Industrial Technologies, University of Trento, 38050 Mesiano (TN), Italy \\ c Dipartimento di Chimica Inorganica, Metallorganica ed Analitica, Università degli Studi di Milano, Via Venezian 21, 20133 Milano, Italy
}

\section{A R T I C L E I N F O}

\section{Article history:}

Received 15 September 2009

Received in revised form 15 February 2010

Accepted 20 February 2010

Available online 26 February 2010

\section{Keywords:}

N-doped nanotitania

Synchrotron radiation X-ray diffraction

$\mathrm{NO}_{x}$ degradation

Unconventional methylene blue removal

Paramagnetic sites

\begin{abstract}
A B S T R A C T
$\mathrm{N}$-doped $\mathrm{TiO}_{2}$ nanocrystals were successfully synthesized by a controlled sol-gel reaction at $\mathrm{pH} 9$ followed by calcinations at $400{ }^{\circ} \mathrm{C}$. Triethylamine was used to modulate the $\mathrm{N}$ content of the samples. The photocatalytic activity was tested using a solar irradiation source with regard to two different pollutants: $\mathrm{NO}_{x}$ (in the gas phase) and methylene blue (MB), deposited onto the oxide film. In the case of $\mathrm{MB}$ degradation the disappearance of the (MB) blue colour was measured directly onto the solid, by means of UV-vis-NIR diffuse reflectance spectroscopy. The final mineralization of the organic molecule was assessed by COD determinations. All $\mathrm{N}$-doped samples produce a better removal of both pollutants than the undoped and commercial samples. By coupling structural (by X-ray synchrotron radiation) and morphological (HRTEM, BET, granulometry) characterizations with spectroscopic analyses (EPR and XPS), the presence of paramagnetic centers, defects, edge dislocations and surface states is appreciated and found to affect the material photocatalytic behaviour.
\end{abstract}

(C) 2010 Elsevier B.V. All rights reserved.

\section{Introduction}

An enormous interest has been devoted, in recent years, to heterogeneous photocatalysis using oxide semiconductors owing to its potential applications to both environmental and energetic issues. Titanium dioxide, $\mathrm{TiO}_{2}$, is characterized by chemical and structural stability, non-toxicity and cheapness, so that it represents one of the most important oxides employed in several fields of photochemistry, e.g. in environmental remediation, photoelectrolysis of water and in dye-sensitized solar cells [1-5]. With a 3.0-3.2 eV band-gap, $\mathrm{TiO}_{2}$ absorbs relatively little of the solar spectrum.

To shift the absorption edge to longer wavelength $(>400 \mathrm{~nm})$ doping of titania with metals ( $\mathrm{V}, \mathrm{Mo}$, Ru, etc.) has been proposed, but often metal ions dopant may act as recombination centers of $\mathrm{e}^{-}$and $\mathrm{h}^{+}[4]$. Recently the anion-doped $\mathrm{TiO}_{2}$ has attracted considerable attention due to its reported activity in the visible light. The $\mathrm{N}$-doped $\mathrm{TiO}_{2}$ seems to be the most promising among all the so-called second generation photocatalysts. Asahi et al. [6] first suggested that $\mathrm{N}$ doping reduces the band-gap due to the mixing of $\mathrm{N}$ $2 \mathrm{p}$ with the $\mathrm{O} 2 \mathrm{p}$ states. Since then, there has been a great number of publications describing enhanced visible light photochemistry in $\mathrm{N}$-doped $\mathrm{TiO}_{2}$ although current debate on the fundamental under-

\footnotetext{
* Corresponding author. Tel.: +39 0250314228; fax: +39 0250314228

E-mail address: giuseppe.cappelletti@unimi.it (G. Cappelletti).
}

standing of the electronic and structural aspects of these materials is wide open [7-12]. Some authors [10,11] proposed that electronic transitions from localized nitrogen states (located close to the valence band edge) to the conduction band of the metal oxide were responsible for visible light response. Ihara et al. [12] and Serpone and co-workers $[8,13]$ affirm, instead, that oxygen vacancies, stabilized by the presence of nitrogen as a result of charge compensation, may act as colour centers, imparting visible light response.

Recent results by Ohsawa et al. [9] show that $\mathrm{N}$ doping of both $\mathrm{TiO}_{2}$ polymorphs results in a red shift in the optical absorption spectrum which is interpreted as due to the generation of $\mathrm{N} 2 \mathrm{p}$ states that extend the valence band into the visible. Bellardita et al. [14] very recently observed that N-doped samples with different light absorption and photocatalytic features could be obtained, depending on the preparation procedure and adopted $\mathrm{TiO}_{2}$ precursor.

Also the structural localization of $\mathrm{N}$ species in the $\mathrm{TiO}_{2}$ lattice is a very debated aspect. Either substitutional or interstitial locations are proposed in the literature also on the grounds of EPR and XPS spectroscopy data [13].

The above described results underline how a generalization of the relations between composition/structure and electronic structure/photochemical properties is very difficult to obtain since slight variations in the preparative procedure may lead to largely different materials. These effects are so complex also due to the heteroge- 
neous, multiple orientation and defective nature of nanoparticle assemblies.

It is important to realize that frequently $\mathrm{N}$-doped materials are inactive in photo-oxidation, although absorbing visible light. Indeed, photogenerated charge carriers do not impart directly photoactivity since recombination phenomena might hinder them to reach the metal oxide surface.

Different methods are presented in the literature [13-17] to incorporate nitrogen in titanium dioxide; the most common procedure implies the use of $\mathrm{NH}_{3}$ or of $\mathrm{NH}_{4} \mathrm{Cl}$. Actually, in some cases, residual ammonium species may be trapped in the lattice at the end of calcination giving rise to spurious XPS signals [15].

On the grounds of what reported above, in this work triethylamine, in increasing amounts, is used as nitrogen source to obtain a series of $\mathrm{N}$-doped $\mathrm{TiO}_{2}$ samples. The doping effect on the photoactivity is measured with respect to two different reactions: the degradation of $\mathrm{NO}_{x}$ in the gas phase and the degradation $\mathrm{MB}$ directly onto the $\mathrm{TiO}_{2}$ film. In this latter case both discoloration and mineralization analyses of $\mathrm{MB}$, deposited onto the oxide film, are performed. Structural characterization (by X-ray synchrotron radiation) and spectroscopic analyses (EPR and XPS), are used to interpret the photocatalytic results.

\section{Experimental}

\subsection{Synthesis of bare and nitrogen-doped $\mathrm{TiO}_{2}$ nanoparticles}

Pure and doped titania samples were synthetized by sol-gel route; titanium (IV) isopropoxide was used as the starting material and triethylamine as nitrogen source. All reactants employed in this work were purchased by Aldrich and used without any other purification treatment; doubly distilled water passed through a Milli-Q apparatus was used to prepare solutions. Firstly, titanium precursor $(30.7 \mathrm{~mL})$ and 2-propanol $(37.6 \mathrm{~mL})$ were put into a $500 \mathrm{~mL}$ reactor with stirring for about $10 \mathrm{~min}$ to form a solution. A variable amount of triethylamine was used and then a $\mathrm{KOH}$ aqueous solution $(180 \mathrm{~mL})$ was added dropwise under vigorous stirring $(300 \mathrm{rpm})$. The same stirring continued after the completion of addition. A transparent fluid gel was formed for high N/Ti ratio. The molarity of the basic solution was adjusted to fix the $\mathrm{pH}$ around 9, while the water/alkoxide molar ratio was 100 and the water/2-propanol molar ratio was 20 .

The wet precursor was dried in oven as a xerogel $\left(80^{\circ} \mathrm{C}\right.$ overnight) and subsequently calcined at $400^{\circ} \mathrm{C}$ for 6 h under oxygen $\operatorname{stream}(9 \mathrm{NL} / \mathrm{h})$.

As synthetized yellowish powders of nitrogendoped titanium dioxide were denoted as $\mathrm{TN}_{-} x$, with $x=0.01-0.05-0.10-0.20-0.40-0.50$, because of the initial $\mathrm{N} / \mathrm{Ti}$ molar ratio. The undoped sample, prepared with the same procedure without triethylamine, was labelled as T.

Two different commercial samples were used to evaluate the photocatalytic performances with respect to the home-made samples: UV100 (by Sachtleben), pure anatase $(\langle D\rangle=10 \mathrm{~nm})$, characterized by large surface area $\left(S_{\mathrm{BET}}=354 \mathrm{~m}^{2} \mathrm{~g}^{-1}\right)$ and A_136 (Alfa Aesar), pure anatase $(\langle D\rangle=18 \mathrm{~nm})$, with surface area comparable with the doped samples $\left(S_{\mathrm{BET}}=136 \mathrm{~m}^{2} \mathrm{~g}^{-1}\right)$.

\subsection{Sample characterization}

X-ray diffraction measurements were conducted on the ID31 high-resolution powder diffraction beamline at the European Synchrotron Radiation Facility (ESRF). Data were collected from $2^{\circ}$ to $75^{\circ} 2 \theta$ in Debye-Scherrer capillary geometry using a wavelength of $0.3999284 \AA$ at a speed of $2^{\circ} 2 \theta / \mathrm{min}$ : the detector system includes a set of 9 silicon analyzers [18]. Wavelength was calibrated using the NIST SRM 640b Silicon standard, while the instrumental reso- lution function was parameterised on the pattern of the NIST SRM 660a Lanthanum hexaboride powder. The qualitative identification of the phase composition was performed with the X'Pert Highscore 2.2 software (PANAlytical b.v., Almelo, The Netherlands). The quantification conducted via the Rietveld method [19] as implemented in the TOPAS 4.2 software (Bruker AXS, Karlsruhe, Germany). The Whole Powder Pattern Modelling (WPPM) method [20-22] was employed for the microstructural analysis of the powders. The instrumental contribution was obtained by parameterising a large set of peak profiles from the NIST SRM 660a standard according to the Caglioti et al. [23] relationship.

The BET surface area was determined by multipoint BET method using the adsorption data in the relative pressure $\left(p / p_{0}\right)$ range of 0.05-0.3. Desorption isotherms were used to determine the pore size distribution using the Barret-Joyner-Halander (BJH) method with cylindrical pore size.

The particle populations of selected samples were analyzed by a BECKMAN COULTER N4 analyzer. The instrument uses Photon Correlation Spectroscopy (PCS), which determines particle size by measuring the rate of fluctuations in laser light intensity scattered by particles as they diffuse through a fluid.

X-ray photoelectron spectra (XPS) were taken in an Mprobe apparatus (Surface Science Instruments). The source was monochromatic $\mathrm{Al} \mathrm{K} \mathrm{K}_{\alpha}$ radiation $(1486.6 \mathrm{eV})$ as in Ref. [24]. The accuracy of the reported $\mathrm{BE}$ can be estimated to be $\pm 0.2 \mathrm{eV}$.

HRTEM measurements were performed on a JEOL JEM-2100 URP microscope equipped with a Gatan Ultrascan 1000 CCD camera (2048 $\times 2048$ pixels). Operating at $200 \mathrm{kV}$, the microscope reaches a point resolution of $0.19 \mathrm{~nm}$ and a line resolution of $0.14 \mathrm{~nm}$ : scale calibration was done on the Au (100) planes. Both dry and wet depositions were performed with ethanol and water as solvent. The best separation was obtained using water (micrographs of water dispersed powders are presented). Powders were deposited on carbon coated copper grids.

For the characterization of the light absorption features and band-gap determinations, diffuse reflectance spectra (DRS) of the powders were measured on a UV-vis scanning spectrophotometer (Perkin-Elmer, Lambda 35), which was equipped with a diffuse reflectance accessory. $\mathrm{A} \mathrm{TiO}_{2}$ thin film was placed in the sample holder on integrated sphere for the reflectance measurements. A "total white" Perkin-Elmer reference material was used as the reference.

Electron paramagnetic resonance (EPR) spectra have been collected at room temperature by means of a Bruker Elexsys spectrometer at the working frequency of about $9.4 \mathrm{GHz}$. The spectral simulations were obtained by the Bruker SimFonia programme [25].

\subsection{Photocatalytic experiments}

The photoactivity of the synthesized samples was tested with respect to two different systems: (a) the degradation of $\mathrm{NO}_{x}$ in the gas phase, and (b) the degradation of $\mathrm{MB}$ on the "dry" $\mathrm{TiO}_{2}$ film. In both cases the same irradiating source was adopted: a 300 W solar lamp (Radium Sanolux HRC 300-280) emitting in the $380-600 \mathrm{~nm}$ wavelength range (radiation intensity of $I=1.2 \times 10^{-5}$ Einstein $\mathrm{dm}^{-3} \mathrm{~s}^{-1}$ ). $\mathrm{TiO}_{2}$ films were prepared by drop casting on glass supports ( 35 and $100 \mathrm{~cm}^{2}$ for $\mathrm{NO}_{x}$ and $\mathrm{MB}$, respectively) of a fixed amount of the powder (20 and $40 \mathrm{mg}$ for $\mathrm{NO}_{x}$ and $\mathrm{MB}$, respectively) dispersed in 2-propanol $(5 \mathrm{~mL})$ and by successive evaporation of the solvent $\left(40^{\circ} \mathrm{C}\right)$. The powders were finely grinded before the deposition to improve the homogeneity of the final layers.

(a) In the photocatalytic degradation of nitrogen oxides the immobilized photocatalyst was set into the pyrex reactor (with a 
volume of $50 \mathrm{~L}$ ) and irradiated with the solar lamp described above at room temperature. The relative humidity was kept constant in all the runs (50\%). Air, $\mathrm{NO}_{x}$ and $\mathrm{N}_{2}$ gas streams were mixed to obtain the desired concentration (500 ppb), introduced inside the photoreactor and the photodegradation products concentrations ( $\mathrm{NO}$ and $\mathrm{NO}_{2}$ ) were continuously monitored by an on-line chemiluminescent analyzer (Teledyne Instruments M200E). Degradation time was limited at $120 \mathrm{~min}$ due to the instrumental detection limit for $\mathrm{NO}_{x}$ concentration below $20 \mathrm{ppb}$. Blank tests in the dark and experiments in the absence of photocatalyst were performed to assess the extent of $\mathrm{NO}_{x}$ adsorption onto $\mathrm{TiO}_{2}$ layer (ca. 15\% after $120 \mathrm{~min}$ ) and of direct photolysis ( $<5 \%$ after $120 \mathrm{~min}$ ).

(b) In the case of $\mathrm{MB}$ removal the $\mathrm{TiO}_{2}$ film was impregnated by $500 \mu \mathrm{L}$ of methylene blue (MB), giving a $60 \pm 5 \mathrm{~cm}^{2}$ stain, in ethanol solution $(0.02 \mathrm{M})$ and allowed to dry. The films were subsequently irradiated in air by the solar lamp for $7 \mathrm{~h}$ at room temperature; the position of the lamp $(35 \mathrm{~cm})$ was selected such as to produce an irradiated area matching the $\mathrm{MB}$ stain one. The degradation of MB deposited onto the $\mathrm{TiO}_{2}$ film was analyzed by following both the disappearance of the blue colour and also the final molecule mineralization. The disappearance of the MB blue colour was followed by analyzing directly the MB impregnated oxide by diffuse reflectance spectra acquired in the vis-NIR range from 350 to $1200 \mathrm{~nm}$ using a JASCO/UV/vis/NIR spectrophotometer model V-570 equipped with a barium sulphate integrating sphere. A block of mylar was used as reference sample following a previously reported procedure [26]. The discoloration of MB was assessed on the grounds of $L^{*}, a^{*}$ and $b^{*}$ parameters adopting the procedure recommended by the Commission Internationale de l'Eclairage (CIE) $[26,27]$. By this method the parameter $L^{*}$ represents the brightness of a sample; a positive $L^{*}$ value stays for a light colour while a negative one corresponds to a dark colour; $a^{*}$ represents the green $(-) \rightarrow$ red $(+)$ axis and $b^{*}$ the blue $(-) \rightarrow$ yellow $(+)$ axis.

COD (chemical oxygen demand) determinations were performed, after extraction of MB from the scratched powder with a fixed amount of $\mathrm{HCl}$ solution, to assess the amount of oxygen required to oxidize the organic compound to carbon dioxide and water. COD values (reported as \% mineralization) are normalized with respect both to the specific surface area of the oxide and to the initial MB (non-irradiated) COD value $(730 \pm 10 \mathrm{mg} / \mathrm{L})$.

\section{Results and discussion}

\subsection{X-rays analysis}

Synchrotron radiation X-ray diffraction was employed for the structural/microstructural characterization of the powders. With respect to traditional laboratory instruments, the ID31 beamline at the ESRF has a higher resolution, higher brilliance (necessary to optimize the signal/noise ratio) and extremely low instrumental contribution to the diffraction pattern. The possibility of working
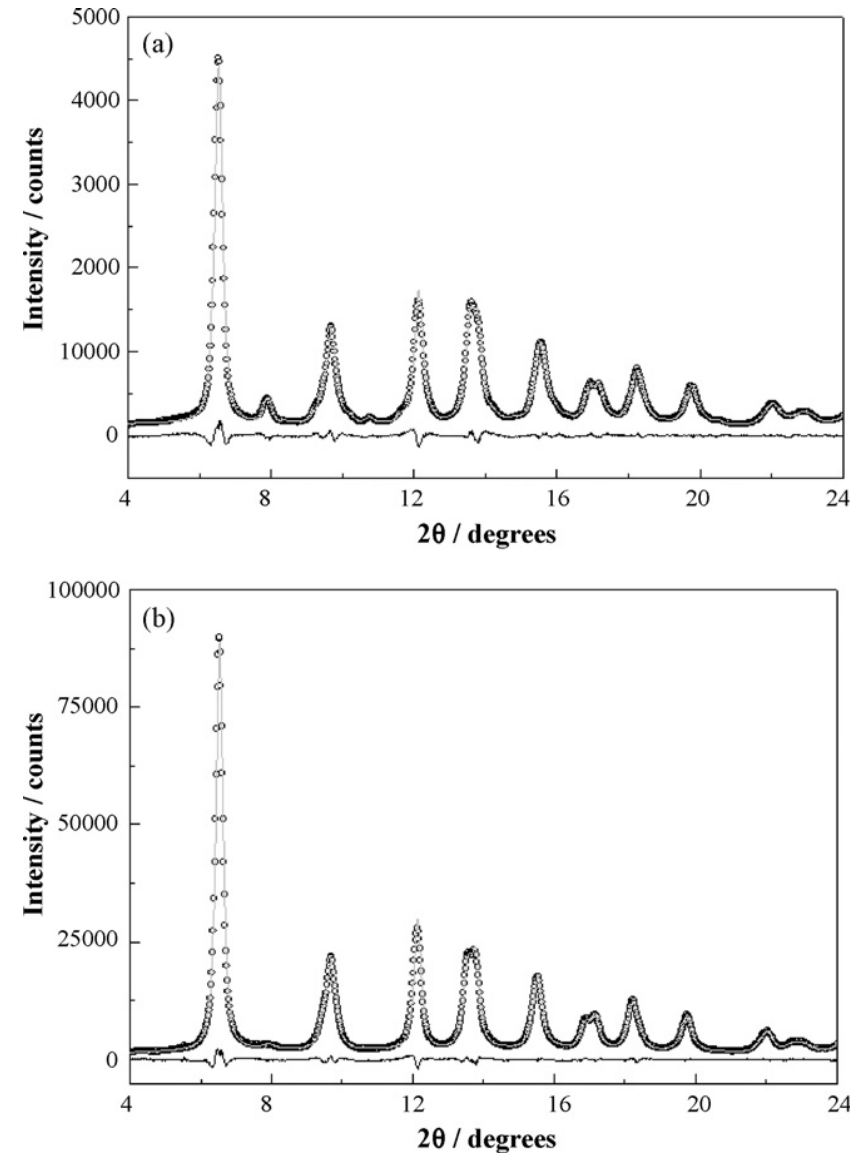

Fig. 1. Low angle part of the SR X-ray diffraction pattern for (a) TN_0.10 and (b) TN_0.40 specimen. Raw data (dots) are presented together with the WPPM result (line) and the difference curve (line, below) for both diffraction lines.

at low wavelength allows a large portion of the reciprocal space to be measured, data of paramount importance for a microstructural analysis.

The qualitative phase identification shows the presence in all specimens of just the anatase and brookite polymorphs of titania. A quantification conducted via the Rietveld method (as apparent in Fig. 1a and b) shows the progressive increase of anatase with increasing nitrogen content (going from ca. $77 \%$ to $90 \%$ from T through TN_0.50, see Table 1, 2nd column): the increase is not linear and it apparently starts with $\mathrm{N} / \mathrm{Ti}$ at 0.20 . A large fraction of nitrogen seems therefore beneficial for the stability of anatase versus brookite. The WPPM physical models for the microstructure are refined directly on the whole diffraction pattern. In the present case, the model assumptions were quite limited: domains were assumed to be spherical and distributed according to a lognormal distribution. Dislocations were selected as the main defect in the powder, responsible for possible anisotropy in the line profile broadening.

Table 1

Structural (anatase weight\%, anatase and brookite domain sizes, anatase edge dislocation) and morphological (BET surface area, total pore volume) for all home-made samples.

\begin{tabular}{llllll}
\hline Sample & wt\%ana & $\left\langle D_{\text {ana }}\right\rangle(\mathrm{nm})$ & $\left\langle D_{\text {bro }}\right\rangle(\mathrm{nm})$ & $\rho_{\text {edge }}\left(\times 10^{15} \mathrm{~m}^{-2}\right)$ & $S_{\text {BET }}\left(\mathrm{m}^{2} \mathrm{~g}^{-1}\right)$ \\
\hline T & $77 \pm 2$ & $4.8 \pm 0.1$ & $6.6 \pm 0.2$ & 0 & 171 \\
TN_0.01 & $76 \pm 2$ & $4.8 \pm 0.1$ & $5.5 \pm 0.2$ & $1.4 \pm 0.9$ & 163 \\
TN_0.05 & $80 \pm 2$ & $5.2 \pm 0.1$ & $6.9 \pm 0.2$ & $1.5 \pm 0.8$ & 0.44 \\
TN_0.10 & $79 \pm 2$ & $4.9 \pm 0.1$ & $9.0 \pm 0.4$ & $5.7 \pm 0.6$ & 0.28 \\
TN_0.20 & $80 \pm 2$ & $5.7 \pm 0.1$ & $1.5 \pm 0.2$ & $4.8 \pm 0.5$ & 0.48 \\
TN_0.40 & $88 \pm 2$ & $5.8 \pm 0.1$ & $1.2 \pm 0.3$ & $0.8 \pm 0.3$ & 9.10 \\
TN_0.50 & $90 \pm 2$ & $5.9 \pm 0.1$ & $1.3 \pm 0.3$ & $3.6 \pm 0.4$ & 0.02 \\
\hline
\end{tabular}


The microstructure analysis results, in terms of mean and variance of the lognormal distribution, are shown in Table 1, 3rd and 4th columns. A slight monotonic increase in the size of the anatase domains $\left\langle D_{\text {ana }}\right\rangle$ can be observed with increasing N/Ti molar ratios. In the case of brookite, instead, the maximum $\left\langle D_{\text {bro }}\right\rangle$ domain is obtained for $\mathrm{N} / \mathrm{Ti}=0.10$, whereas for higher nitrogen concentrations $(\mathrm{N} / \mathrm{Ti}>0.20)$, a collapse of the brookite sizes is noted. The 5th column of Table 1 reports the density of edge dislocations appreciated in the $\mathrm{N}$-doped samples: TN_0.10 shows the maximum content.

\subsection{Morphological characterization}

The specific surface areas and pore volumes of the home-made samples are reported in Table 1 (columns 6th and 7th): both surface area and pore volume are shown to progressively decrease with increasing the $\mathrm{N}$ content in the synthesis. These effects can be related in part with the increase in the domain size observed by XRD, but possibly also with the progressive occurrence of sintering phenomena, leading to larger aggregates for high $\mathrm{N}$ contents. In fact the distribution of the aggregate size $\left\langle D_{\text {gran }}\right\rangle$ by granulometry appears to be monomodal, centred around $500-300 \mathrm{~nm}$ for lower $\mathrm{N} / \mathrm{Ti}$ molar ratios, while for higher values the relevant presence of much bigger aggregates ( $>10000 \mathrm{~nm}$ ) can be appreciated.

The high-resolution transmission electron micrographs presented in Fig. 2 confirm the XRD and BET results in terms of approximate average size and size uniformity. The tendency of agglomeration, observed by granulometric measurements and indirectly by BET, is clear: it is quite difficult to observe isolated particles in the powders, the tendency to high superposition increasing with increasing nitrogen content. The various domains are well crystallised, but in some of them the effects of the deformation field caused by the presence of dislocations can be observed.

\subsection{XPS analyses}

Survey XPS spectra were recorded for all samples. No significant presence of impurities was observed, except for the ubiquitous carbon contaminant. In the case of the latter element, only the $\mathrm{C} 1 \mathrm{~s}$ peak at $284.6 \mathrm{eV}$ (due to $-\mathrm{CH}$ - species) was present, with average $\mathrm{Ti} / \mathrm{C}$ atomic ratios always in the range $0.60-0.70$.

The $\mathrm{N} / \mathrm{Ti}$ atomic ratios of the present samples are reported in Table 2 (2nd column). These latter values are all lower (around one order of magnitude) than the starting molar ratios adopted in the synthesis of the samples. Apparently an appreciable loss of $\mathrm{N}$ containing species occurs during calcination, as previously reported [7]. Further, XPS atomic ratios, which pertain to the subsurface region, do not show an increasing trend with increasing the $\mathrm{N}$ amount adopted in the synthesis, but range around 0.02 for all samples.

The peaks of Ti 2 p are always regular showing the expected doublet with a binding energy (BE) of Ti $2 \mathrm{p}_{3 / 2}$ at $458.6 \pm 0.2 \mathrm{eV}$ which is typical of Ti (IV) in the oxide [28,29].

Fig. 3a and $b$ reports the $N$ 1s region of samples TN_0.50 (Fig. 3a) and TN_0.10 (Fig. 3b), respectively. The shape of the peak in Fig. 3a shows the presence of a single component, centred at $399.5 \mathrm{eV}(\mathrm{A})$; the shape of the peak is common to the samples with the higher initial content (TN_0.40 and TN_0.50). By contrast, the TN_0.10 and TN_0.20 samples show peaks which are broad and complex being formed, respectively, by two or three components (see Table 2). The debate on the attribution of XPS $\mathrm{N}$ 1s peak components to specific species or structures is definitely open and amply discussed in the literature [13,30,31]. Peaks in the range (396-404 eV) were observed by several authors and variably attributed; generally peaks at 396-397 eV were attributed to substitutional nitrogen (O-Ti-N linkages) while peaks at higher BE were attributed to oxi-
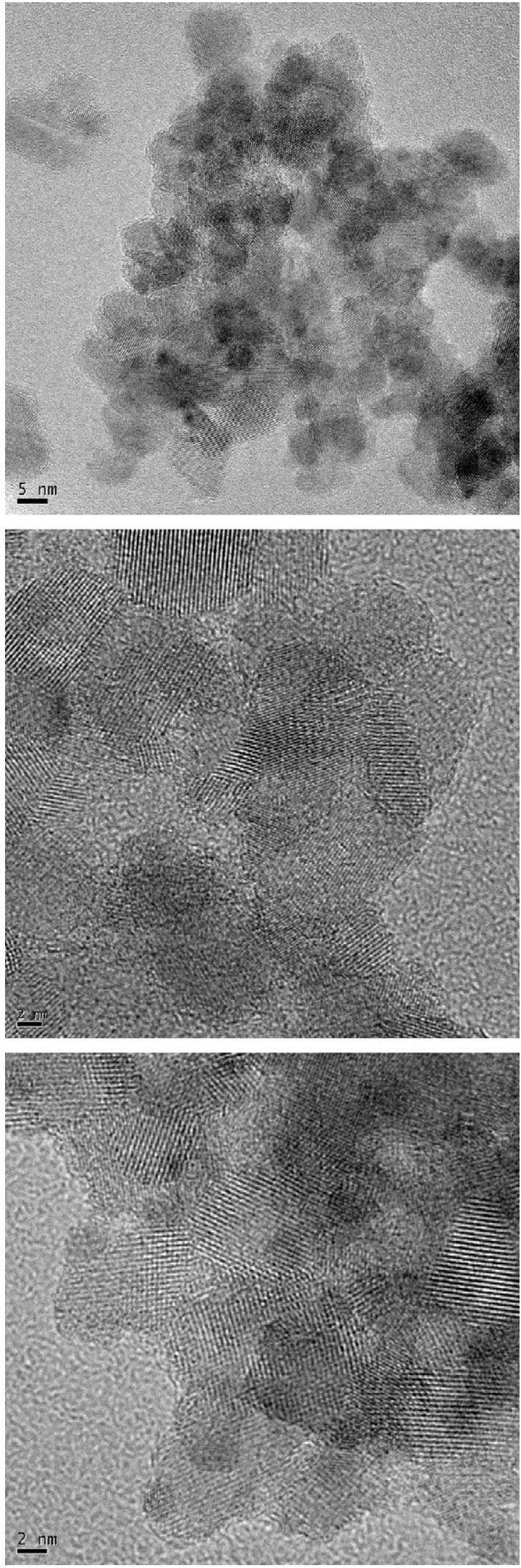

Fig. 2. HRTEM images of T, TN_0.10 and TN_0.50 samples. 

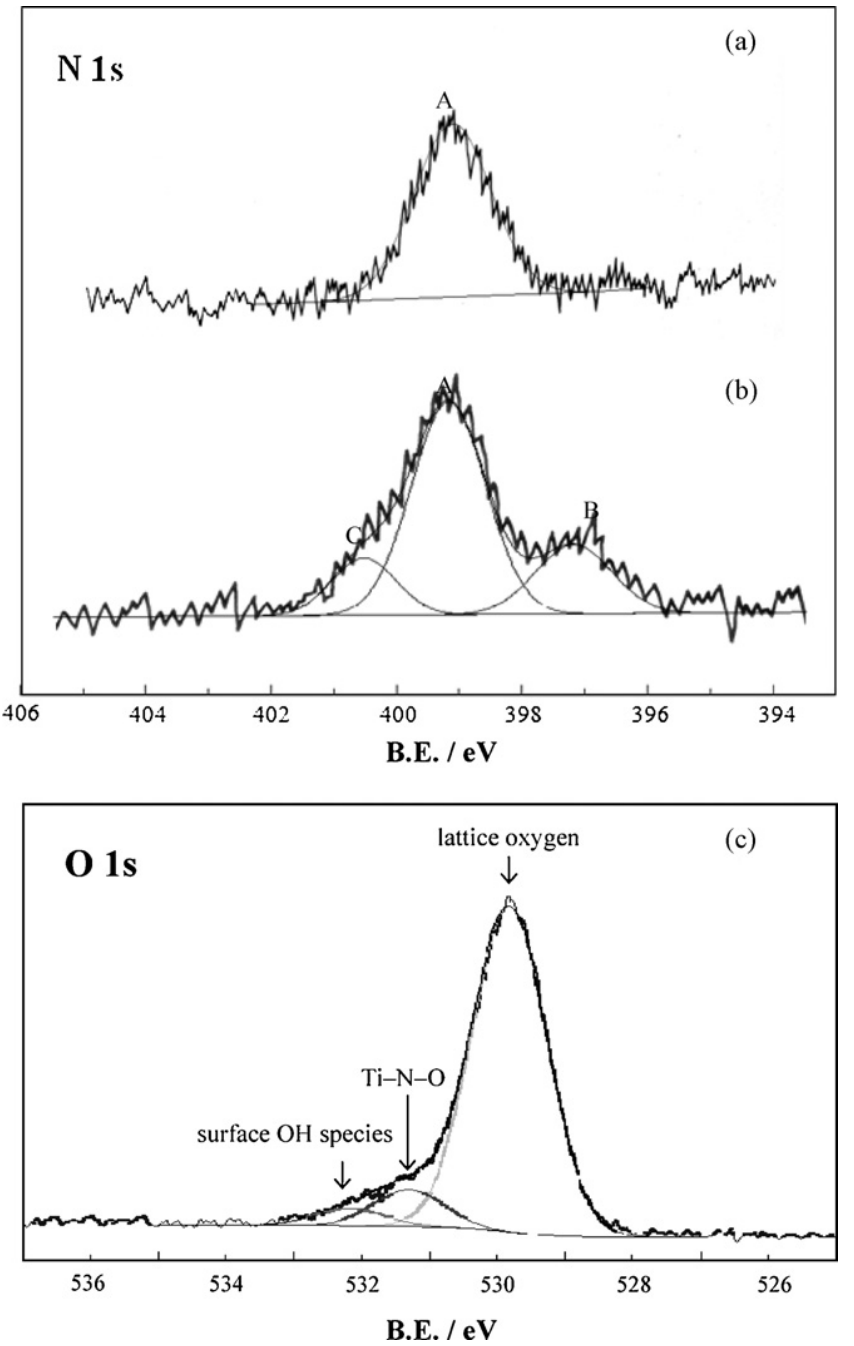

Fig. 3. XPS spectra: (a and b) $N$ 1s region for TN_0.50 and TN_0.10 samples; (c) $01 \mathrm{~s}$ region.

dized nitrogen ( $\mathrm{N}-\mathrm{O}-\mathrm{Ti}-\mathrm{O}$ species) or to chemisorbed species $\left(\mathrm{NH}_{4}\right.$, $\mathrm{N}_{2}$ ) $[13,30,31]$. In the present case it can be suggested that the peak/component centred at ca. $399 \mathrm{eV}(\mathrm{A})$, present in all samples, is relative to oxidized nitrogen, possibly in interstitial location. All samples show a $\mathrm{N} 1 \mathrm{~s}$ peak at this $\mathrm{BE}$ and this is the major peak component also in the case of TN_0.10 and TN_0.20 samples. The peak component centred at 396-397 eV, present in both TN_0.10 and TN_0.20, can be attributed to substitutional $\mathrm{N}\left(\mathrm{O}^{2-}\right.$ ions substituted by $\mathrm{N}^{2-}$ anions [13]). This seems to find some support also in XRD data: the maximum of edge dislocation content (Table 1, 5th

Table 2

XPS results (N/Ti atomic ratios and N 1s binding energies) and "apparent" band-gap values (by DRS determinations) for home-made samples.

\begin{tabular}{|c|c|c|c|c|c|}
\hline \multirow[t]{2}{*}{ Sample } & \multirow{2}{*}{$\begin{array}{l}\mathrm{N} / \mathrm{Ti} \\
\text { (atomic ratio) }\end{array}$} & \multicolumn{3}{|c|}{ N 1s BE (eV) } & \multirow{2}{*}{$\begin{array}{l}\text { "Apparent" } \\
\text { band-gap (eV) }\end{array}$} \\
\hline & & $\mathrm{N}-\mathrm{Ti}$ & $\mathrm{N}-\mathrm{O}$ & $\mathrm{a}$ & \\
\hline $\mathrm{T}$ & - & - & - & - & 3.21 \\
\hline TN_0.01 & - & - & - & - & 3.12 \\
\hline TN_0.05 & - & - & - & - & 3.03 \\
\hline TN_0.10 & 0.022 & 397.1 & 399.1 & 400.5 & 2.98 \\
\hline TN_0.20 & 0.022 & 396.4 & 399.7 & - & 2.95 \\
\hline TN_0.40 & 0.018 & - & 399.2 & - & 2.92 \\
\hline TN_0.50 & 0.019 & - & 399.5 & - & 2.85 \\
\hline
\end{tabular}

${ }^{\mathrm{a}}$ The attribution of this peak cannot be straightforward (see the text). column) and of the size of the brookite phase is reached just for the TN_0.10 specimen. The attribution of the peak component at $400.5 \mathrm{eV}(\mathrm{C})$ instead is not straightforward. This peak component can be either assigned again to a nitrogen atom in the environment O-Ti-N, following the attribution of Bellardita et al. [14] or, differently, it can be attributed to molecularly chemisorbed species, on the grounds of what reported by Nakamura et al. [32].

The 01 s spectra revealed, in all cases, the presence of various components (Fig. 3c). The XPS oxygen 1s peak of oxides is, as a rule, complex and shows the presence of more than one component. The oxygen peak is generally fitted by two components, corresponding, respectively, to oxygen in the oxide lattice (ca. $530 \mathrm{eV}$ ) and surface $\mathrm{OH}$ groups or un-dissociated water (ca. $532 \mathrm{eV}$ ) $[7,33]$. The shape of the peak in Fig. 3c suggests the presence of a further component at intermediate binding energies. The presence of components different from those typical of oxides, in the case of $\mathrm{N}$ doped samples, have been observed in the literature and differently attributed. In the present case it can be suggested that the component at intermediate BE (ca. $531.5 \mathrm{eV}$ ) is the result of Ti-O-N or of Ti-N-O structures [29,31], as commented above in the case of $\mathrm{N} 1 \mathrm{~s}$ regions.

\subsection{Optical features}

Fig. 4a reports the comparison among the diffuse reflectance (DR)UV-vis spectra of the present samples. The curves relative to $\mathrm{N}$-doped samples differ from those of bare $\mathrm{TiO}_{2}$ for the broad absorption in the visible region, in analogy with what previously reported for $\mathrm{N}$-doped $\mathrm{TiO}_{2}[15,34]$. With increasing the starting $\mathrm{N}$ amount in the samples the absorption edge reveals shifts toward higher wavelengths.

Experimental data of diffuse reflectance were converted to absorption coefficient values $F(R)$ according to the Kubelka-Munk
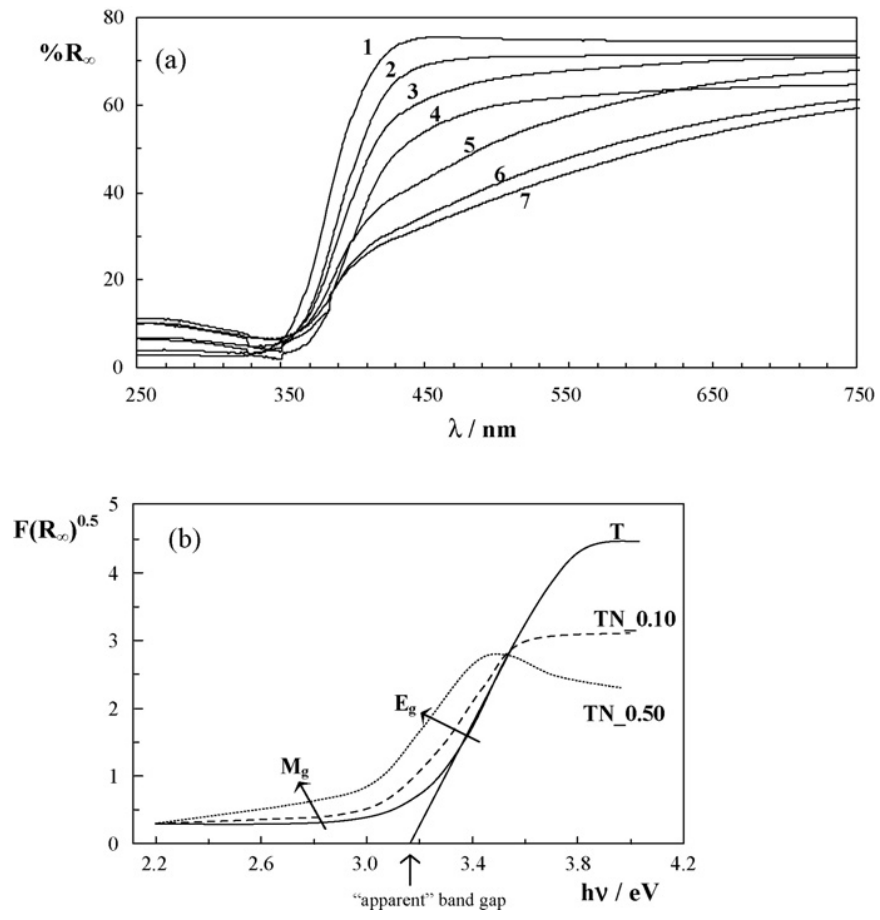

Fig. 4. (a) Diffuse reflectance spectra for all home-made samples (1: T, 2: TN_0.01, 3: TN_0.05, 4: TN_0.10, 5: TN_0.20, 6: TN_0.50, 7: TN_0.40). Note the inversion in the sequence between TN_0.50 and TN_0.40; (b) Kubelka-Munk elaboration for T, TN_0.10 and TN_0.50 ( $E_{g}=$ band-gap, $M_{g}=$ mid gap). 
equation $[35,36]$ :

$F\left(R_{\infty}\right)=\frac{\left(1-R_{\infty}\right)^{2}}{2 R_{\infty}}$

where $F\left(R_{\infty}\right)\left(R_{\infty}=R_{\text {sample }} / R_{\text {standard }}\right)$ is the absorption coefficient.

The theory of interband optical absorption shows that at the absorption edge, the absorption coefficient of a semiconductor can be expressed as

$\left[F\left(R_{\infty}\right) h v\right]^{n}=A\left(h v-E_{g}\right)$

where $A$ is a constant, $E_{g}$ is the band-gap of allowed transitions $(\mathrm{eV}), h$ is the Planck's constant $\left(6.62608 \times 10^{-34} \mathrm{Js}\right), v$ is the frequency of the light $\left(\mathrm{s}^{-1}\right)$, and $n$ is a number characterizing the transition process. This term takes the value of $1 / 2$ for an indirect $\mathrm{TiO}_{2}$ allowed transition. Therefore, a transformed Kubelka-Munk function can be constructed by plotting $\left[F\left(R_{\infty}\right)\right]^{0.5}$ against the energy of excitation source to obtain the band-gap of $\mathrm{TiO}_{2}$ particles. The converted curves were fitted by a Boltzmann sigmoidal equation and the band-gap value was obtained by the $x$-axis intercept of the line tangent to the inflection point of the curve.

Fig. 4 b reports, for selected samples, the transformed reflectance as a function of the photon energy for the present samples. The corresponding "apparent" band-gap values obtained by this procedure for all samples are reported in Table 2 (6th column). The values show a progressive decrease with increasing the $\mathrm{N}$ content of the samples. It should be emphasized that the "apparent" band-gap values reported in Table 2 do not necessarily correspond to an actual rigid upward shift of the valence band edge toward the conduction band of $\mathrm{TiO}_{2}$, but they can be the result of electronic transitions from intragap localized levels up to the conduction band. Further, in the case of the N-doped samples (Fig. 4b) the slope of the curves in the low energy region, suggests, in analogy with what reported by other authors $[13,37]$, the presence of midgap band(s) $\left(M_{g}\right)$ located above the valence band. At variance with what reported by Bellardita et al. [14], however, in the present case a sharp absorption edge, in the low energy region, could not be singled out. It can be suggested, also on the grounds of EPR results reported in the following, that spectra in this region are the result of overlapping bands, due to electron transitions, also involving F-type centers. The slope of the curves increases in passing from TN_0.10 to TN_0.50 in analogy with the increase in $\mathrm{F}^{+}$sites (see in the following, Fig. 6b). Actually literature calculations of energy levels of F-type centers gave energies for the $\mathrm{F}, \mathrm{F}^{+}, \mathrm{F}^{2+}$ centers, respectively, of $0.87,1.78$ and $0.2 \mathrm{eV}[13,37]$ below the bottom of the conduction band, in agreement with the energy region of the midgap bands observed presently in Fig. $4 \mathrm{~b}$.

\subsection{Photocatalytic experiments}

\subsection{1. $\mathrm{NO}_{x}$ photodegradation in the gas phase}

The $\mathrm{NO}_{x}$ concentration is the sum of the $\mathrm{NO}$ and $\mathrm{NO}_{2}$ concentrations; the general mechanism of photodegradation of $\mathrm{NO}_{x}$, implies the oxidation of the nitric monoxide to nitric acid or nitrous by reactive species at the $\mathrm{TiO}_{2}$ surface. In the present case no increase in activity was observed by increasing the catalyst amount, consequently, it was concluded that only the exposed/external fraction of the catalyst was irradiated [28].

The photodegradation of $\mathrm{NO}_{x}$ was very fast; all oxides reached conversions larger than $90 \%$ in $80-90$ min reaction time. Fig. 5 reports, as an example, the degradation curve for a representative sample (TN_0.10). In order to produce a significant comparison among the present samples, experimental data relative to the first $40 \mathrm{~min}$ of reaction time were elaborated on the grounds of a first order kinetic law (Fig. 5). The experimental points are interpolated by linear regressions with high correlation coefficients. The rate

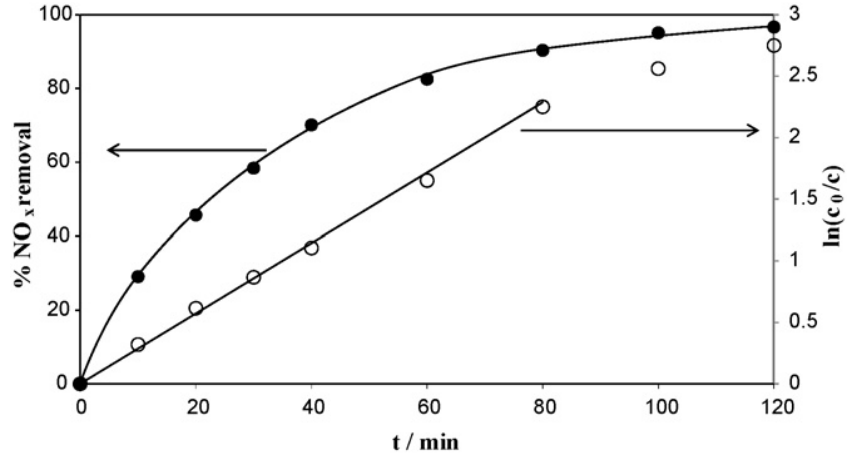

Fig. 5. Photocatalytic $\mathrm{NO}_{x}$ degradation and logarithmic plot adopted to obtain the rate constant by a simplified first order rate equation for a selected sample(TN_0.10).

constants (Table 3 ) show a significant increase starting from the undoped sample value and up to the $0.05-0.10$ samples and then level off to a quasi plateau region. The reaction path for $\mathrm{NO}_{x}$ conversion is an oxidation either directly supported by valence band holes or indirectly by $\mathrm{OH}$ radicals. The mediation by $\mathrm{OH}$ radicals is supported by the key role played by humidity in the reaction so that the following oxidation reactions can be proposed:

$\mathrm{NO}_{2}+\mathrm{OH}^{\bullet} \rightarrow \mathrm{HNO}_{3}$

$\mathrm{NO}+\mathrm{OH}^{\bullet} \rightarrow \mathrm{HNO}_{2}$

\subsubsection{MB photoremoval}

The photocatalytic activity of the present samples with respect to the degradation of MB, deposited onto the oxide film, was followed by both DRS colorimetric analyses (performed directly onto the solid) and by COD determinations (after extraction of the residual MB from the powders) to assess the final mineralization of the organic molecule.

(CIE) $L^{*}, a^{*}$ and $b^{*}$ parameters [26], obtained by elaboration of DRS spectra in the vis-NIR region, were used to give information on the MB deposited onto the oxide. The disappearance of the MB blue colour is described jointly by the value of $b^{*}$, which becomes less negative in correspondence to lighter colour hues and by the $L^{*}$ (the larger the value the higher the brightness) parameters. In the case of UV irradiation the commercial UV100 sample showed the best discoloration in terms of both $L^{*}$ and $b^{*}$ parameters (see Table 1 Supplementary Material). In the case, instead, of irradiation by solar lamp (Fig. 6a) enhanced performances were achieved for all the N-doped samples with respect to the commercial ones (UV100 and A_136), except for the sample with the lowest $\mathrm{N}$ initial amount (TN_0.01). All samples are grouped at the less negative side of the $b^{*}$ axis with respect to the reference blue sample $\left(\mathrm{REF}, \mathrm{MB}+\mathrm{TiO}_{2}\right.$, without irradiation); this indicates that all the irradiated materials show a less intense blue hue, corresponding to a partial disappearance of the MB molecule. Among the doped samples no regular trend of the

Table 3

Initial ( $40 \mathrm{~min}$ ) pseudo-first order kinetic constants and relative correlation coefficients for home-made and commercial samples in the case of $\mathrm{NO}_{x}$ degradation in gas phase.

\begin{tabular}{lll}
\hline Sample & $\kappa^{40} \times 10^{2}\left(\mathrm{~min}^{-1}\right)$ & $R^{2}$ \\
\hline T & $2.47 \pm 0.06$ & 0.996 \\
TN_0.01 & $2.86 \pm 0.07$ & 0.997 \\
TN_0.05 & $3.02 \pm 0.09$ & 0.996 \\
TN_0.10 & $3.22 \pm 0.05$ & 0.999 \\
TN_0.20 & $2.97 \pm 0.08$ & 0.991 \\
TN_0.50 & $2.88 \pm 0.02$ & 0.998 \\
UV100 & $2.78 \pm 0.04$ & 0.989 \\
A_136 & $1.96 \pm 0.02$ & 0.986 \\
\hline
\end{tabular}



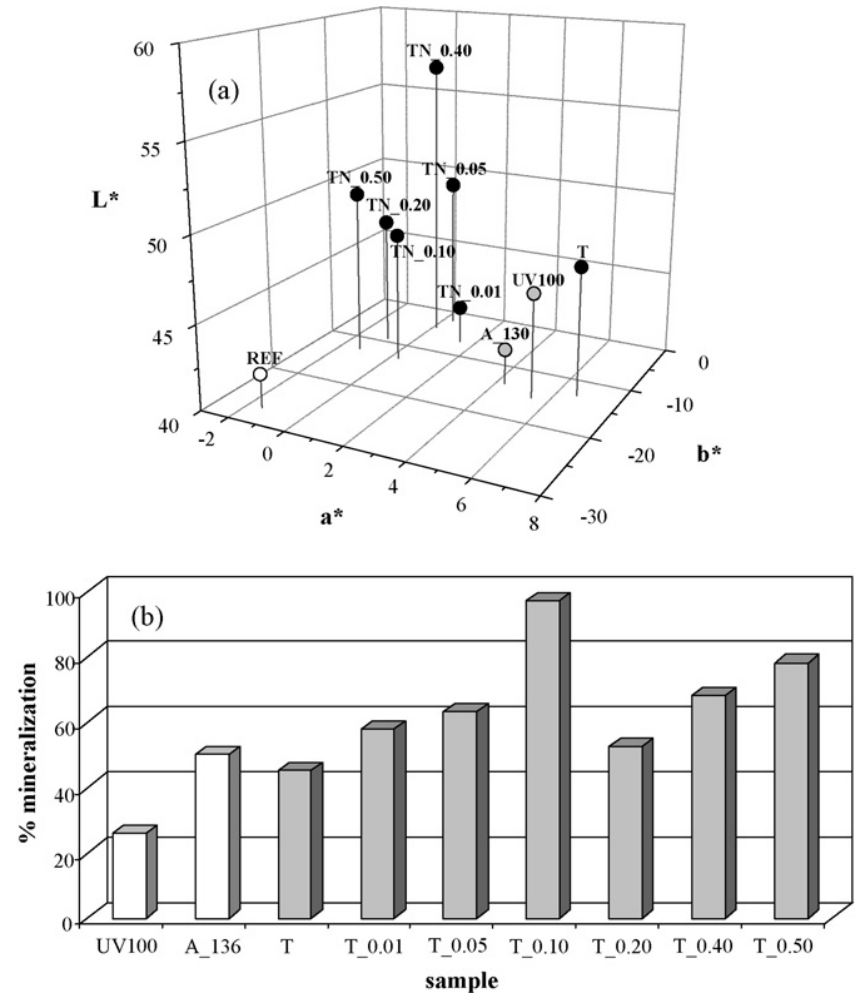

Fig. 6. (a) Discoloration efficiency $\left(L^{*} a^{*} b^{*}\right.$ parameters) and (b) relative $\%$ mineralization by COD determinations for all samples.

discoloration with the $\mathrm{N}$ initial amount is appreciable. It should be considered that differences in the oxides surface area may also affect the discoloration efficiency. TN_0.40 appears to be the most active oxide showing the largest $L^{*}$ and very negative $b^{*}$ values.

The discoloration of MB does not necessarily correspond to the oxidation and mineralization of the molecule; in fact there exists a reduced form of MB (LMB, leuco) which is colourless [38]. Different degradative routes and intermediates are reported in the literature to degrade MB $[38,39]$. To verify if the discoloration apparent in Fig. 6 a is the result of the formation of LMB or of the actual molecule mineralization, COD determinations were performed at the end of the reaction. Fig. $6 \mathrm{~b}$ reports the oxygen demand as a function of the $\mathrm{N}$ amount in the $\mathrm{TiO}_{2}$ samples. All doped samples are more active than commercial and undoped ones. The performances progressively increase with the $\mathrm{N}$ content up to an optimum for sample TN_0.10 (10\% initial N/Ti molar ratio) attaining lower values at even higher N/Ti molar ratios. It is interesting to note that the samples producing either best discoloration (TN_0.40) or best mineralization (TN_0.10) are not the same. Further, it can be recalled that the sample (TN_0.10) producing the best MB mineralization and $\mathrm{NO}_{x}$ degradation shows the complex XPS pattern (Fig. 3b) with also substitutional $\mathrm{N}$ sites and the largest content of edge dislocations.

The lack of coincidence between the best performing samples, with respect to either discoloration or mineralization, can be the result of different routes followed by MB during irradiation.

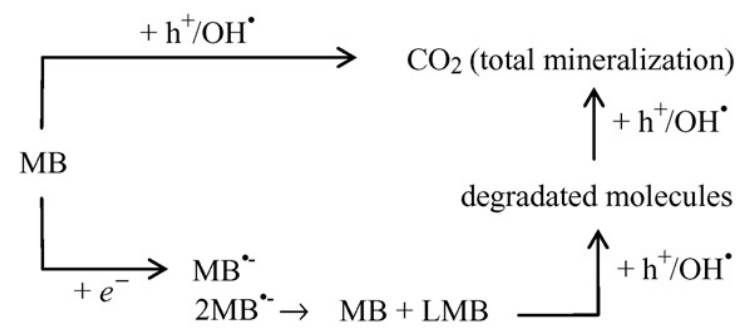

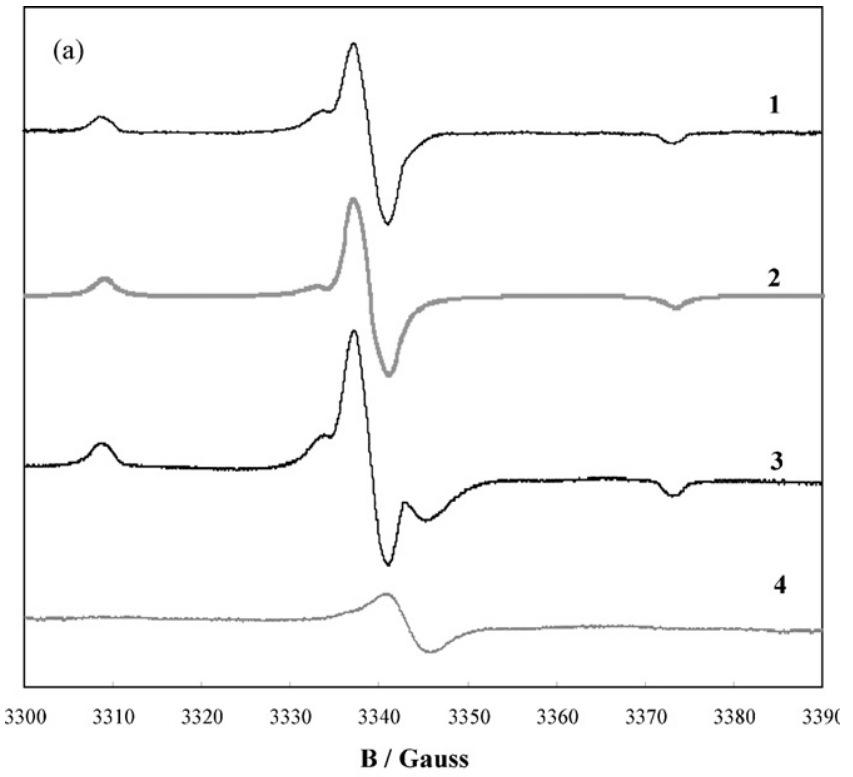

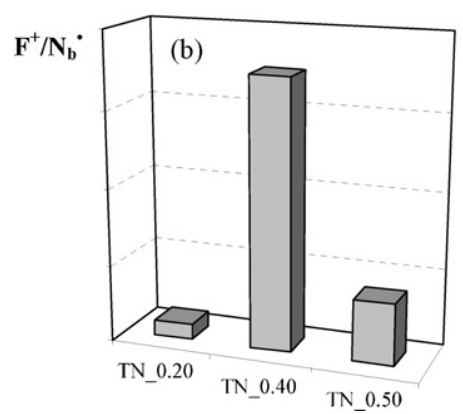

Fig. 7. (a) EPR spectra obtained at room temperature: (1) TN_0.10, (2) TN_0.10 simulation, (3) $\mathrm{N} / \mathrm{Ti} \geq 0.20$ and (4) difference between curve 3 and 2 multiplied by 1.36 ; (b) $\mathrm{F}^{+} / \mathrm{N}_{\mathrm{b}} \cdot$ ratio for samples with initial molar ratio $\mathrm{N} / \mathrm{Ti} \geq 0.20$.

The molecule can be either transformed into LMB through reduction by electrons in the conduction band or oxidized, by interactions with the valence band holes or native $\mathrm{OH}^{\bullet}$ species, starting with a demethylation step to be finally mineralized. For long reaction times also LMB can be further degradated and mineralized.

\subsection{EPR analyses}

EPR measurements have been performed to analyze the paramagnetic species, induced in the samples by the $\mathrm{N}$ doping itself.

The EPR pattern of all the $\mathrm{N}$-doped samples is characterized by an intensity increasing with increasing the $\mathrm{N} / \mathrm{Ti}$ starting ratio. Fig. 7a (curve 1) reports, as an example, the curve of TN 0.10 . The spectral profile was simulated by hypothesizing an unpaired electron with Zeeman energy parameters $g_{x}=2.0066$; $g_{y}=2.0054$; $g_{z}=2.0040$ and interacting with a nuclear magnetic moment $I=1$ through the hyperfine coupling parameters $A_{x} \approx A_{y} \approx 3 \mathrm{G}$ and $A_{z} \approx 32.2 \mathrm{G}$ (Fig. 6 a, curve 2 ). Similar patterns have been reported in [40] and attributed to different species, located in the bulk of the $\mathrm{N}-\mathrm{TiO}_{2}$ microcrystals. Furthermore, theoretical calculations [41] led to attribute features like these to $\mathrm{N}_{\mathrm{s}}$ (substitutional) or to $\mathrm{N}_{\mathrm{i}}$ (interstitial) doping nitrogen atoms, both giving very similar EPR patterns, not resolvable from each other. Therefore these species will be simply indicated by $\mathrm{N}_{\mathrm{b}}{ }^{\bullet}$, i.e. as bulk nitrogen paramagnetic defects [15]. A second paramagnetic component appears in the EPR spectrum of samples with the $\mathrm{N} / \mathrm{Ti} \geq 0.20$ (Fig. 7a, curve 3 ). In order to single out the contribution of this latter component a subtraction procedure between curve 3 and curve 2 (multiplied by 1.36) was 
performed. This line (Fig. 7a, curve 4) was Lorentzian-shaped, with $g=2.0023$ and peak-to-peak width of $5 \mathrm{G}$. This feature is attributed to paramagnetic $\mathrm{F}^{+}$centers, also on the grounds of the optical results (Fig. 7a and b). F centers can occur in oxides as the result of oxygen vacancies. In the case of $\mathrm{N}$-doped $\mathrm{TiO}_{2}$ the formation of oxygen vacancies is supported by charge compensation mechanisms, ensuing the presence of $\mathrm{N}$ in the lattice. The following reactions, for the formation of $\mathrm{F}$ centers can be proposed:

$\mathrm{V}_{\mathrm{O}} \bullet+2 \mathrm{e}^{-} \rightarrow \mathrm{V}_{\mathrm{O}}(\mathrm{F})$

$\mathrm{V}_{\mathrm{O}} \bullet+1 \mathrm{e}^{-} \rightarrow \mathrm{V}_{\mathrm{O}}^{\bullet}\left(\mathrm{F}^{+}\right)$

where $\mathrm{V}_{\mathrm{O}}{ }^{\bullet \bullet}$ is an electron-pair deficient oxygen vacancy (anion vacancy, $\mathrm{F}^{++}$center).

It has been demonstrated that the fundamental level of $\mathrm{F}^{+}$is energetically lower than that of F centers [13].

With increasing the N/Ti starting ratio the overall spectral intensity of the samples increases, and, at the same time, also the $\mathrm{F}^{+} / \mathrm{N}_{\mathrm{b}}{ }^{\bullet}$ ratio is observed to increase up to $\mathrm{N} / \mathrm{Ti}=0.4$ and then to level off (Fig. 7b). The increase of the dopant $\mathrm{N}$ in $\mathrm{TiO}_{2}$ is reported to produce a parallel increase in oxygen vacancies, due to the lowering of the energy threshold for their formation [15]; however, a trend comparable to the one reported in Fig. $7 \mathrm{~b}$ has not been reported previously, to the authors best knowledge.

EPR characterizations can help to further interpret results from the photocatalytic activity of the samples. It can be proposed that the two different paramagnetic species present in the N-doped $\mathrm{TiO}_{2}$ samples promote two reaction paths: (i) the oxidation and final mineralization of both $\mathrm{NO}_{x}$ and $\mathrm{MB}$ are supported by $\mathrm{N}_{\mathrm{b}} \bullet$ centers, which are generally reported to behave as strong oxidizers; (ii) the reduction of $\mathrm{MB}$ to $\mathrm{LMB}$, instead, may be promoted by $\mathrm{F}^{+}$ centers, able to donate one electron, giving the doubly charged $\mathrm{F}^{++}$ centers (anion vacancy). The TN_0.40 sample shows the best discoloration of MB (Fig. 6a), in accordance with its top content of $\mathrm{F}^{+}$centers. Indeed, the most efficient sample for both pollutants mineralization is actually the TN_0.10 sample which contains the maximum amount of $\mathrm{N}_{\mathrm{b}}{ }^{\bullet}$ centers, in the absence of $\mathrm{F}^{+}$centers. Apparently the best performance for the oxidation reactions shown by TN_0.10 suggests that the concomitant presence of $\mathrm{N}_{\mathrm{b}}{ }^{\bullet}$ and $\mathrm{F}^{+}$ centers reduces the photocatalytic activity, due to the occurrence of recombination processes. It is interesting to compare the best $\mathrm{NO}_{x}$ and MB mineralization efficiency of TN_0.10 with the dislocation content in anatase: the best mineralization is observed when the maximum of edge dislocations is achieved (TN_0.10, see Table 1, 5th column).

Upon ageing, the EPR features of the samples undergo appreciable modifications, especially in the case of samples showing the presence of $\mathrm{F}^{+}$centers. By storing the prepared $\mathrm{N}-\mathrm{TiO}_{2}$ samples, as dry powders in closed vessels for long time lengths (months), the

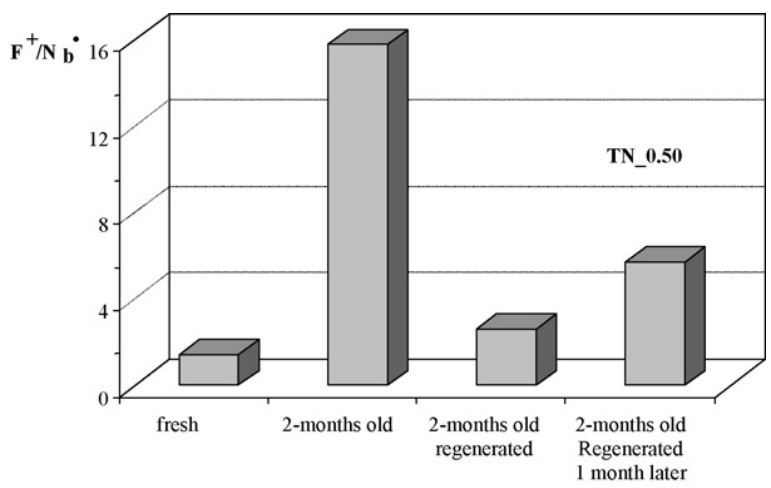

Fig. 8. $\mathrm{F}^{+} / \mathrm{N}_{\mathrm{b}} \cdot$ ratio for fresh, aged and regenerated TN_0.50 sample.
$\mathrm{F}^{+} / \mathrm{N}_{\mathrm{b}}$ is observed to increase leading to samples containing only $\mathrm{F}^{+}$paramagnetic centers. Upon heating the samples, in air, the initial $\mathrm{F}^{+} / \mathrm{N}_{\mathrm{b}}$ is almost restored. Fig. 8 reports, as an example, the case of sample TN_0.50. The following forward reaction can be proposed to take place upon ageing:

$\mathrm{N}_{\mathrm{b}} \cdot+\mathrm{F} \leftrightarrows \mathrm{N}_{\mathrm{b}}^{-}+\mathrm{F}^{+}$

The energetically favoured reduction of $\mathrm{N}_{\mathrm{b}} \bullet$ occurs upon standing in a poor oxygen containing environment, while the backward reaction occurs by heating in oxidizing conditions.

\section{Conclusions}

A series of $\mathrm{N}$-doped $\mathrm{TiO}_{2}$ samples were prepared by a sol-gel procedure, from titanium (IV) isopropoxide, at $\mathrm{pH} 9$, using triethylamine as the nitrogen source. The calcination at $400^{\circ} \mathrm{C}$ promoted the crystallization yielding anatase-brookite composite nanocrystals showing increasing anatase content with increasing the starting N/Ti ratio. Larger nitrogen contents appear, therefore, to be beneficial for the stability of anatase versus brookite.

The starting N/Ti molar ratio appeared to affect also the nature of the paramagnetic species present in the samples: for $\mathrm{N} / \mathrm{Ti}<0.2$ only the $\mathrm{N}_{\mathrm{b}} \cdot$ paramagnetic species, already described in the literature for $\mathrm{N}$-doped samples could be appreciated. For higher N/Ti atomic ratios a second paramagnetic species was observed which, also on the grounds of optical determinations, was interpreted as a colour $\mathrm{F}^{+}$center. The $\mathrm{F}^{+} / \mathrm{N}_{\mathrm{b}}$ increases reaching a maximum for $\mathrm{N} / \mathrm{Ti}=0.40$. The balance between the two different paramagnetic species was affected also by ageing the dry powders for long times (months): the $\mathrm{F}^{+} / \mathrm{N}_{\mathrm{b}} \cdot$ was observed to increase leading to samples containing only $\mathrm{F}^{+}$paramagnetic centers. Upon heating the samples in air the initial $\mathrm{F}^{+} / \mathrm{N}_{\mathrm{b}}$ ' was almost restored. Such effect was not previously reported in the literature.

The photoactivity was tested with respect to the $\mathrm{NO}_{x}$ degradation in gas phase and to the "dry" degradation of methylene blue deposited onto the oxide film. This latter experiment are unconventional for photocatalysis, since dyes are, as a rule, photodegradated in solution. A further distinctive aspect of this procedure lies in the direct evaluation of the disappearance of the blue colour directly on the film by means of $C-L^{*} a^{*} b^{*}$ elaboration of diffuse reflectance spectroscopy data. The final mineralization of the dye molecule was also, independently, verified by COD determinations. For both pollutant reactions, under solar irradiation, the $\mathrm{N}$-doped samples were more active than the corresponding bare $\mathrm{TiO}_{2}$ and the two commercial samples, probably due to their greater photon absorption. The sample showing the best $\mathrm{NO}_{x}$ degradation and $\mathrm{MB}$ mineralization is the one showing the top content of $\mathrm{N}_{\mathrm{b}}{ }^{\bullet}$ species in the absence of $\mathrm{F}^{+}$centers. Instead the best $\mathrm{MB}$ discoloration is produced by the sample showing the largest $\mathrm{F}^{+} / \mathrm{N}_{\mathrm{b}} \bullet$ ratio. To the authors best knowledge no similar finding is present in the literature. It can be suggested that $\mathrm{F}^{+}$centers, able to donate one electron to give the doubly charged $\mathrm{F}^{++}$center (anion vacancy) may reduce MB to LMB.

The best oxidation/mineralization efficiency is presented by a sample having both interstitial and substitutional $\mathrm{N}$ species and also showing the maximum content of edge dislocations. It can be suggested that the active $\mathrm{N}_{\mathrm{b}}{ }^{\bullet}$ centers correspond to nitrogen trapped on the edge dislocation line (and dragged by it) and interacting with the deformation field of the dislocation.

\section{Acknowledgements}

The authors wish to thank Dr. Emmanuel Garnier of Universitè de Poitiers for the HRTEM determinations. This research has been supported by the University of Milan Research Funds (FIRST, PUR). 


\section{Appendix A. Supplementary data}

Supplementary data associated with this article can be found, in the online version, at doi:10.1016/j.apcatb.2010.02.027.

\section{References}

[1] G. Cappelletti, S. Ardizzone, C.L. Bianchi, S. Gialanella, A. Naldoni, C. Pirola, V. Ragaini, Nanoscale Res. Lett. 4 (2009) 97-105.

[2] M. Anpo, Bull. Chem. Soc. Jpn. 77 (2004) 1427-1442.

[3] M. Graetzel, Nature 414 (2001) 338-344.

[4] M. Anpo, M. Takeuchi, J. Catal. 216 (2003) 505-516.

[5] G. Cappelletti, C.L. Bianchi, S. Ardizzone, Appl. Catal. B: Environ. 78 (2008) 193-201.

[6] R. Asahi, T. Morikawa, T. Ohwaki, K. Aoki, Y. Taga, Science 293 (2001) 269-271.

[7] C.L. Bianchi, G. Cappelletti, S. Ardizzone, S. Gialanella, A. Naldoni, C. Oliva, C. Pirola, Catal. Today 144 (2009) 31-36.

[8] A.V. Emeline, G.N. Kuzmin, N. Serpone, Chem. Phys. Lett. 454 (2008) 279-283.

[9] T. Ohsawa, I. Lyubinetsky, Y. Du, M.A. Henderson, V. Shutthanandan, S.A. Chambers, Phys. Rev. B 79 (2009) 085401-085407.

[10] H. Irie, Y. Watanabe, K. Hashimoto, J. Phys. Chem. B 107 (2003) 5483-5486.

[11] T. Lindgren, J.M. Mwabora, E. Avandano, J. Jonsson, A. Hoel, C.-G. Granquist, S.-E. Lindquist, J. Phys. Chem. B 107 (2003) 5709-5716.

[12] T. Ihara, M. Miyoshi, Y. Iriyama, O. Matsumoto, S. Sugihara, Appl. Catal. B: Environ. 42 (2003) 403-409.

[13] A.V.Emeline, V.N. Kuznetsov, V.K. Rybchuk, N. Serpone, Int. J. Photoenergy 2008 (2008) 1-19.

[14] M. Bellardita, M. Addamo, A. Di Paola, L. Palmisano, A.M. Venezia, Phys. Chem. Chem. Phys. 11 (2009) 4084-4093.

[15] S. Livraghi, M.C. Paganini, E. Giamello, A. Selloni, C. Di Valentin, G. Pacchioni, J. Am. Chem. Soc. 128 (2006) 15666-15671.

[16] N. Serpone, J. Phys. Chem. B 110 (48) (2006) 24287-24293.

[17] S. Sato, R. Nakamura, S. Abe, Appl. Catal. A: Gen. 284 (2005) 131-137.

[18] J.-L. Hodeau, P. Bordet, M. Anne, A. Prat, A.N. Fitch, E. Dooryhee, G. Vaughan, A. Freund, SPIE Proc. 3448 (1998) 353-361.
[19] R.A. Young, The Rietveld Method, Oxford University Press, 1993.

[20] P. Scardi, M. Leoni, Acta Crystallogr. A58 (2002) 190-200.

21] P. Scardi, M. Leoni, M. D'Incau, Z. Kristallogr. 222 (2007) 129-135.

22] M. Leoni, T. Confente, P. Scardi, Z. Kristallogr. Suppl. 23 (2006) 249-254.

[23] G. Caglioti, A. Paoletti, F.P. Ricci, Nucl. Instrum. Methods 3 (1960) 223-228.

[24] S. Ardizzone, C.L. Bianchi, G. Cappelletti, A. Naldoni, C. Pirola, Environ. Sci Technol. 42 (2008) 6671-6676.

[25] C. Oliva, L. Bonoldi, S. Cappelli, L. Fabbrini, I. Rossetti, L. Forni, J. Mol. Catal. A: Chem. 226 (2005) 33-40.

[26] S. Ardizzone, G. Cappelletti, P. Fermo, C. Oliva, M. Scavini, F. Scimè, J. Phys. Chem. B 109 (2005) 22112-22119.

[27] CIE, Recommendations on Uniform Colour Spaces, Colour Difference Equations, Psychometrics Colour Terms. Supplement No. 2 of CIE Publ. No. 15 (EI-1.31) 1971. Bureau Central de la CIE, Paris, 1978.

[28] S. Ardizzone, C.L. Bianchi, G. Cappelletti, S. Gialanella, C. Pirola, V. Ragaini, J. Phys. Chem. C 111 (2007) 13222-13231.

[29] J.F. Moulder, W.F. Stickle, K.D. Bomben, Handbook of X-ray Photoelectron Spectroscopy, Perkin Elmer, Eden Praie, 1992.

[30] T.L. Thompson, J.T. Yates Jr., Top. Catal. 35 (3-4) (2005) 197-210.

[31] E. György, A. Pérez del Pino, P. Serra, J.L. Morenza, Surf. Coat. Technol.173 (2003) 265-270.

[32] R. Nakamura, T. Tanaka, Y. Nakato, J. Phys. Chem. B 108 (2004) 10617-10620.

33] S. Ardizzone, C.L. Bianchi, G. Cappelletti, F. Porta, J. Catal. 227 (2004) 470-478.

[34] C. Di Valentin, E. Finazzi, G. Pacchioni, A. Selloni, S. Livraghi, M.C. Paganini, E. Giamello, Chem. Phys. 339 (2007) 44-56.

[35] G.F.A. Kortum, Reflectance Spectroscopy: Principles, Methods, Applications, New York, 1969

[36] G. Burgeth, H. Kisch, Coord. Chem. Rev. 230 (2002) 41-47.

[37] V.N. Kuznetsov, N. Serpone, J. Phys. Chem. C 113 (2009) 15110-15123.

[38] C. Yogi, K. Kojima, T. Takai, N. Wada, J. Mater. Sci. 44 (2009) 821-827.

[39] T. Zhang, T. Oyama, A. Aoshima, H. Hidaka, J. Zhao, N. Serpone, J. Photochem. Photobiol. A: Chem. 140 (2001) 163-172.

[40] S. Livraghi, A. Votta, M.C. Paganini, E. Giamello, Chem. Commun. (2005) 498-500.

[41] C. Di Valentin, G. Pacchioni, A. Selloni, S. Livraghi, E. Giamello, J. Phys. Chem. B 109 (2005) 11414-11419. 